\title{
Global Estimates of Land Surface Water Fluxes from SMOS and SMAP Satellite Soil Moisture Data
}

\author{
Morteza Sadeghi, ${ }^{\mathrm{a}}$ Ardeshir Ebtehaj, ${ }^{\mathrm{a}}$ Wade T. Crow,${ }^{\mathrm{b}}$ Lun GaO, ${ }^{\mathrm{a}}$ AdAm J. Purdy, \\ JoshuA B. Fisher, ${ }^{\mathrm{c}}$ SCOTT B. JONEs, ${ }^{\mathrm{d}}$ EBRAHIM BABAEIAN, ${ }^{\mathrm{e}}$ AND MARKUS TulleR ${ }^{\mathrm{e}}$ \\ ${ }^{a}$ Department of Civil, Environmental and Geo-Engineering, University of Minnesota, Minneapolis, Minnesota \\ ${ }^{\mathrm{b}}$ USDA-ARS Hydrology and Remote Sensing Laboratory, Beltsville, Maryland \\ ${ }^{\mathrm{c}}$ Jet Propulsion Laboratory, California Institute of Technology, Pasadena, California \\ ${ }^{\mathrm{d}}$ Department of Plants, Soils and Climate, Utah State University, Logan, Utah \\ ${ }^{\mathrm{e}}$ Department of Environmental Science, The University of Arizona, Tucson, Arizona
}

(Manuscript received 12 July 2019, in final form 3 December 2019)

\begin{abstract}
In-depth knowledge about the global patterns and dynamics of land surface net water flux (NWF) is essential for quantification of depletion and recharge of groundwater resources. Net water flux cannot be directly measured, and its estimates as a residual of individual surface flux components often suffer from mass conservation errors due to accumulated systematic biases of individual fluxes. Here, for the first time, we provide direct estimates of global NWF based on near-surface satellite soil moisture retrievals from the Soil Moisture Ocean Salinity (SMOS) and Soil Moisture Active Passive (SMAP) satellites. We apply a recently developed analytical model derived via inversion of the linearized Richards' equation. The model is parsimonious, yet yields unbiased estimates of long-term cumulative NWF that is generally well correlated with the terrestrial water storage anomaly from the Gravity Recovery and Climate Experiment (GRACE) satellite. In addition, in conjunction with precipitation and evapotranspiration retrievals, the resultant NWF estimates provide a new means for retrieving global infiltration and runoff from satellite observations. However, the efficacy of the proposed approach over densely vegetated regions is questionable, due to the uncertainty of the satellite soil moisture retrievals and the lack of explicit parameterization of transpiration by deeply rooted plants in the proposed model. Future research is needed to advance this modeling paradigm to explicitly account for plant transpiration.
\end{abstract}

\section{Introduction}

The sustainable availability of groundwater for irrigated agriculture and as potable water for over two billion people is crucial for global water and food security (Gurdak 2017). The rapid increase of the human population has amplified the global reliance on groundwater. Consequently, groundwater is being extracted at unsustainably high rates at many locales (Konikow 2011; Wada et al. 2012; Moore and Fisher 2012; Richey et al. 2015). A practical principle for sustainable management of groundwater is to limit water abstraction to a rate smaller than the long-term average groundwater recharge (Finch 1998). In arid and semiarid regions, where lateral groundwater flow is negligible, the groundwater recharge is governed by the land surface net water flux, NWF = infiltration - evapotranspiration (Finch 1998;

Corresponding author: Morteza Sadeghi,msadeghi@umn.edu
Yeh et al. 2007). Therefore, accurate estimation of NWF at the global scale is of paramount importance for sustainable management of groundwater resources.

Despite their importance, global patterns and dynamics of NWF are still poorly understood (National Research Council 2012). Today, the NASA Gravity Recovery and Climate Experiment (GRACE) and GRACE Follow-On satellites provide valuable global observations of the terrestrial water storage (TWS) anomaly (Rodell et al. 2009; Famiglietti et al. 2011; Rodell et al. 2018). Although the TWS temporal rate of change (i.e., the derivative of TWS anomaly with respect to time, denoted as $d S / d t$ ) is intimately connected to NWF, these two fluxes are fundamentally different. In particular, GRACE $d S / d t$ is not only governed by NWF, but also by natural and anthropogenic induced variations of surface water storage, groundwater abstraction, lateral groundwater flow, snowpack variations, and the melting of glaciers (Getirana et al. 2017; Rodell et al. 2018). 
NWF is linked to individual surface flux components, including precipitation $(P)$, evapotranspiration $(\mathrm{ET})$, runoff $(R)$, and irrigation (Ir) via the surface water balance (SWB) equation, $\mathrm{NWF}=P-\mathrm{ET}-R+\mathrm{Ir}$. Salient advances have been made in global monitoring of these flux components using satellite remote sensing (e.g., Stephens and Kummerow 2007; Hou et al. 2014; Ebtehaj et al. 2015; Vinukollu et al. 2011; Fisher et al. 2017; Purdy et al. 2018) and modeling of their spacetime dynamics with hydrologic and land surface models (e.g., Simůnek et al. 2016; Oleson et al. 2008; Niu et al. 2011). However, a global estimation of NWF via the SWB remains challenging due to (i) a lack of direct global observation of the flux components (i.e., $R$ and Ir), and more importantly, (ii) the accumulated uncertainty emanating from individual flux estimation errors (Armanios and Fisher 2014; Pellet et al. 2018, 2019; Padrón et al. 2019). These uncertainties are largely due to errors in remote sensing algorithms (Polhamus et al. 2013; Badgley et al. 2015; Ebtehaj and Kummerow 2017; Purdy et al. 2016), inadequate parameterization of hydrologic models (Liu and Gupta 2007), and a mismatch of the spatiotemporal resolutions of different data products (Demory et al. 2014). Consequently, NWF estimates based on the SWB are often systematically biased and are not able to close the terrestrial water balance.

A potential solution for avoiding closure errors is to estimate NWF directly from strongly correlated state variables such as near-surface soil moisture (SM). Recently, applying satellite SM data, encouraging advances have been made to estimate NWF (Crow et al. 2017) or other flux components such as precipitation (Brocca et al. 2013, 2014; Koster et al. 2016), evapotranspiration (McColl et al. 2017; Purdy et al. 2018; Akbar et al. 2018, 2019), runoff (Koster et al. 2018), and irrigation (Lawston et al. 2017; Brocca et al. 2018; Jalilvand et al. 2019; Zaussinger et al. 2019). To close the water balance, these models generally rely on empirical functional relationships, for example, for the soil internal drainage rate.

Recently, Sadeghi et al. (2019) developed a physically based model to approximate NWF directly from SM data and evaluated its performance with reference data from four flux tower sites in the United States. This model was derived via analytical inversion of Warrick's (1975) solution to the linearized Richards' equation (Richards 1931). An advantage of this model is that it is parsimonious and computationally efficient. In addition, the model parameters can be directly derived from SM data and a single scaling parameter, and the model does not rely on data intensive and computationally demanding least squares calibrations, which enables global NWF approximations from satellite data.

Here, we examine the Sadeghi et al. (2019) NWF model at the global scale, employing SM products from the Soil Moisture and Ocean Salinity (SMOS) (Kerr et al. 2001) and Soil Moisture Active Passive (SMAP) (Entekhabi et al. 2010) satellites to provide direct estimates of the global land surface net water flux. We demonstrate that this model yields unbiased estimates of long-term cumulative NWF which are not readily extractable with the conventional SWB approach. In addition, we illustrate that the NWF model provides a new avenue for global mapping of infiltration and runoff, neither of which can be retrieved directly from space.

\section{Materials and methods}

\section{a. Analytical model}

Richards' (1931) equation captures the soil moisture dynamics in space and time in response to the diffusive and gravitational water flow in variably saturated soil. The soil moisture-based Richards' equation is widely applied in land surface models (Decker and Zeng 2009). The linearized form of this equation is given as

$$
\frac{\partial \theta}{\partial t}=D \frac{\partial^{2} \theta}{\partial z^{2}}-k \frac{\partial \theta}{\partial z},
$$

where $\theta$ is volumetric soil moisture content, $t$ is time, $z$ is soil depth positive downward, $D$ is the effective soil water diffusivity (i.e., an average value for the entire soil moisture range), and $k$ is the average slope of the soil hydraulic conductivity function $K(\theta)$.

Applying the superposition principle, Warrick (1975) analytically solved Eq. (1) to link any arbitrary sequence of downward (soil moisture gain) and upward (soil moisture loss) surface water flux pulses to the soil moisture profile. This solution, which is valid for a semiinfinite homogeneous soil profile with uniform initial soil moisture conditions, variable net water flux at the surface, and constant soil moisture at the bottom boundary, is given as

$$
\begin{array}{rlr}
\Theta_{N}(Z) & =e^{-0.5 Z+0.25 T} F_{1} U(Z, T) & (N=1) \\
& =e^{-0.5 Z+0.25 T}\left\{F_{1} U(Z, T)+\sum_{i=2}^{N}\left(F_{i}-F_{i-1}\right) U[Z,(N-i+1) \Delta T]\right\} & (N>1)
\end{array},
$$


where subscript $i$ denotes the number of time steps (from 1 to $N$ ) at intervals of $\Delta T$, and $T, Z, \Theta$, and $F$ are dimensionless representations of time $t$, soil depth $z$, soil moisture $\theta$, and net water flux $f$, respectively, defined as

$$
\begin{aligned}
& T=\frac{k^{2} t}{D}, \quad Z=\frac{k z}{D}, \quad \Theta=\left(\frac{\theta-\theta_{\infty}}{\theta_{\infty}}\right) e^{-0.5 Z+0.25 T}, \\
& F=\frac{f-k \theta_{\infty}}{k \theta_{\infty}} .
\end{aligned}
$$

In Eq. (3), $D$ is the soil water diffusivity, $k$ is slope of the soil hydraulic conductivity function $K(\theta), \theta_{\infty}$ denotes soil moisture at the bottom boundary, and $U$ is given as

$$
\begin{aligned}
U(Z, T)= & -0.5 e^{Z}(Z+T+1) \operatorname{erfc}\left[0.5\left(\frac{Z}{\sqrt{T}}+\sqrt{T}\right)\right] \\
& +\sqrt{\frac{T}{\pi}} \exp \left\{-\left[0.5\left(\frac{Z}{\sqrt{T}}-\sqrt{T}\right)\right]^{2}\right\} \\
& +0.5 \operatorname{erfc}\left[0.5\left(\frac{Z}{\sqrt{T}}-\sqrt{T}\right)\right] .
\end{aligned}
$$

Inverting Warrick's solution [Eq. (2)], Sadeghi et al. (2019) derived an analytical model that allows approximation of the land surface net water flux from a time series of near-surface soil moisture:

$$
F_{N}=\left\{\begin{array}{lr}
\frac{\Theta_{N}(Z) e^{0.5 Z-0.25 T}}{U(Z, \Delta T)} & (N=1) \\
F_{1}+\frac{\Theta_{N}(Z) e^{0.5 Z-0.25 T}-F_{1} U(Z, T)}{U(Z, \Delta T)} & (N=2) . \\
F_{N-1}+\frac{1}{U(Z, \Delta T)}\left\{\Theta_{N}(Z) e^{0.5 Z-0.25 T}-F_{1} U(Z, T)-\sum_{i=3}^{N}\left(F_{i-1}-F_{i-2}\right) U[Z,(N-i+2) \Delta T]\right\} & (N>2)
\end{array}\right.
$$

While Warrick's solution in Eq. (2) indicates that a surface water flux can be propagated into the entire soil profile, altering soil moisture at different depths (see Fig. 1 in Sadeghi et al. 2019), Eq. (5) specifies that temporal variations of soil moisture at a single depth (such as the surface layer) contain adequate information to inversely estimate the surface water flux.

The analytical nature of Eq. (5) facilitates calculation of NWF for different time steps (e.g., diurnal to monthly) without the "truncation error," which is of a concern in numerical models (Zeng and Decker 2009). Note that the estimated NWF for large (e.g., monthly) time steps determines the cumulative sum of all positive and negative surface fluxes occurring during $\Delta t$ (e.g., submonthly infiltration and evaporation events). Accordingly, positive NWF means dominant infiltration (water gain) and negative NWF means dominant ET (water loss) during time step $\Delta t$.

Performance of Eq. (5) has been evaluated with ground-based reference observations of $P$ and ET from four flux tower sites with different climatic conditions and land covers in the United States (Sadeghi et al. 2019). It has been shown that while the original solution of Warrick (1975) was derived for bare soil, Eq. (5) works well for vegetated sites such as Tonzi Ranch in California with $30 \%-60 \%$ forest canopy cover (Baldocchi et al. 2016). This is expected due to the correlation between soil evaporation and plant transpiration on an annual basis, and because of calibration of the model parameters based on actual NWF data, which include plant transpiration. However, it should be noted that the model does not account for transpiration by deeply rooted plants under dry conditions, when the soil surface dries out and soil evaporation and plant transpiration decouple.

Other simplifying assumptions of the NWF model that may not realistically represent natural conditions are discussed in Sadeghi et al. (2019). For example, nonisothermal water and vapor flow, occurring under dry and warm conditions, and upward water flow from shallow water tables, which is common in wet regions, are not accounted for. Here, we examine to what extent this parsimonious model can capture global NWF dynamics, despite the introduced simplifications.

\section{b. Datasets and preprocessing}

We employed six global data products for estimation and evaluation of NWF that comprise: 1) SMOS-IC soil moisture (Fernandez-Moran et al. 2017) from May 2010 to May 2017 at 25-km grid and 3-day temporal resolution; 2) SMAP-L3 Passive Enhanced soil moisture (O’Neill et al. 2018) from April 2015 to May 2017 at 9-km grid and 3-day temporal resolution; 3) Global Precipitation Climatology Project (GPCP) precipitation (Adler et al. 2003) from May 2010 to May 2017 at $2.5^{\circ}$ grid and monthly temporal resolution; 4) PriestleyTaylor Jet Propulsion Laboratory (PTJPL) evapotranspiration (Fisher et al. 2008) from May 2010 to April 2017 
at 36-km grid and daily temporal resolution; 5) Global Runoff Reconstruction (GRUN) runoff (Ghiggi et al. 2019 a,b) from May 2010 to December 2014 at $0.5^{\circ}$ grid and monthly temporal resolution; and 6) GRACE-CSR TWS anomaly (Save et al. 2016) from May 2010 to May 2017 at $1^{\circ}$ grid and near-monthly (irregular) temporal resolution.

The results in Sadeghi et al. (2019) indicate that the proposed model is sensitive to soil moisture perturbations. Therefore, results for a monthly time scale are more stable than results for diurnal soil moisture data. This is why we considered a monthly time scale for a regular grid with an intermediate resolution of $1^{\circ}$. Datasets with higher spatial resolutions were coarsegrained via box averaging and datasets with lower resolutions were mapped via nearest neighbor interpolation to neither add nor discard relevant spatial information. The daily and 3-day data were averaged to produce the monthly data, which are attributed to the middle of each month. GRACE data at regular monthly resolution was obtained via linear interpolation of the original data.

\section{c. Model calibration and evaluation}

We employed Eq. (5) to globally approximate NWF based on SMOS and SMAP SM data. These new estimates, denoted as $\mathrm{NWF}_{\mathrm{SMO}}$ and $\mathrm{NWF}_{\mathrm{SMAP}}$, are compared with approximations from the residual approach, $\mathrm{NWF}_{\mathrm{RES}}=P-\mathrm{ET}-R$, with irrigation assumed to be negligible, as well as with GRACE $d S / d t$. For these comparisons, we debiased $\mathrm{NWF}_{\mathrm{RES}}$ values to alleviate the uncertainties of its flux components. To that end, we subtracted the $\mathrm{NWF}_{\mathrm{RES}}$ mean from 2010 to 2014, which implies no change in climate or direct human impacts on water storage over said period (Rodell et al. 2015). In addition, the proposed model is examined as a new potential approach for retrieving infiltration and runoff from space. In particular, the $\mathrm{NWF}_{\mathrm{SMO}}$ estimates, in combination with ET and $P$ data, are used to provide global estimates of infiltration $\left(I=\mathrm{NWF}_{\mathrm{SMOS}}+\mathrm{ET}\right)$ and runoff $\left(R=P-\mathrm{ET}-\mathrm{NWF}_{\mathrm{SMOS}}\right)$.

To compute Eq. (5), the mean sensing depth $z$ is set to $2.5 \mathrm{~cm}$ assuming that satellite $\mathrm{SM}$ is representative for the top 5-cm soil layer. Note that the normalized depth $(Z=k z / D)$, and subsequently our results are not overly sensitive to small changes of $z$ near the surface, because the ratio $D / k$ is commonly a much larger length scale than $z$. We performed a sensitivity analysis on $z$ (not shown here) and found only very small changes of the output NWF (below $0.1 \mathrm{~cm}$ month $^{-1}$ globally) in response to the changes of $z$ in the range of $0-5 \mathrm{~cm}$.

A parsimonious approach is used to calibrate the model parameters. The bottom-boundary soil moisture $\theta_{\infty}$ for each pixel is assumed as a long-term mean of SM, a constant $k$ (e.g., $0.3 \mathrm{~cm} \mathrm{month}^{-1}$ ) is assumed for all pixels and $D$ is calculated for each pixel using the following physically based equation (Sadeghi et al. 2019):

$$
D=D^{\prime}\left(\frac{f_{\max }}{f_{\max }^{\prime}}\right)^{2},
$$

where $D^{\prime}$ is an initial arbitrary value for $D$ (e.g., $3000 \mathrm{~cm}^{2}$ month ${ }^{-1}$ ), yielding an initial estimate for the maximum NWF ( $f_{\max }^{\prime}$ ) using Eq. (6), and $f_{\max }$ is the actual maximum NWF. Because $\mathrm{NWF}_{\mathrm{RES}}$ was not available after December 2014, we used SMOS and debiased $N_{W F}$ data (2010-14) to globally map $D$ with Eq. (6) and subsequently used this map to derive both $\mathrm{NWF}_{\mathrm{SMOS}}$ and $\mathrm{NWF}_{\mathrm{SMAP}}$. A step-by-step procedure for calculating NWF from satellite SM retrievals is provided in the appendix.

To determine uncertainties associated with the NWF estimates, we conducted 100 Monte Carlo simulations by perturbing all model inputs via zero-mean random errors. Specifically, we perturbed the monthly values of soil moisture and $f_{\max }$ by a uniformly distributed random error of $\pm 10 \%$ and $\pm 20 \%$, respectively. Then, we calculated the upper and lower NWF uncertainty bounds as 0.95 and 0.05 quantiles of all 100 simulations.

\section{Results and discussion}

The global distribution of the maximum net water flux $f_{\max }$ used in Eq. (6), which is the only tuning parameter of the NWF model, and the soil water diffusivity $D$ resulting from Eq. (6) are presented in Fig. 1. As shown, $D$ varies over several orders of magnitude globally and is generally higher for wetter regions with stronger NWF seasonality (i.e., higher $f_{\max }$ ). The similarity between soil diffusivity and the NWF seasonality pattern is expected from Eq. (6). Within this context, higher diffusivity indicates smaller soil moisture changes in response to a unit net water flux pulse. In practice, this dependency highlights the strong climate impact on soil hydraulic properties (Montzka et al. 2017). For example, in general more diffusive soils are found close to the surface $(0-5 \mathrm{~cm})$ in densely vegetated tropical regions, where the soil bulk density is extremely low due to the high organic matter content (Hengl et al. 2014).

As mentioned earlier, the soil diffusivity map in Fig. 1b was obtained from SMOS data for the period from 2010 to 2014 . Because $D$ is a static soil property, we assume that the global estimates of $D$ do not significantly vary with time and the SM product. To examine this assumption, we recalculated $D$ for the period from January 2015 to May 2017 based on SMAP SM data. 

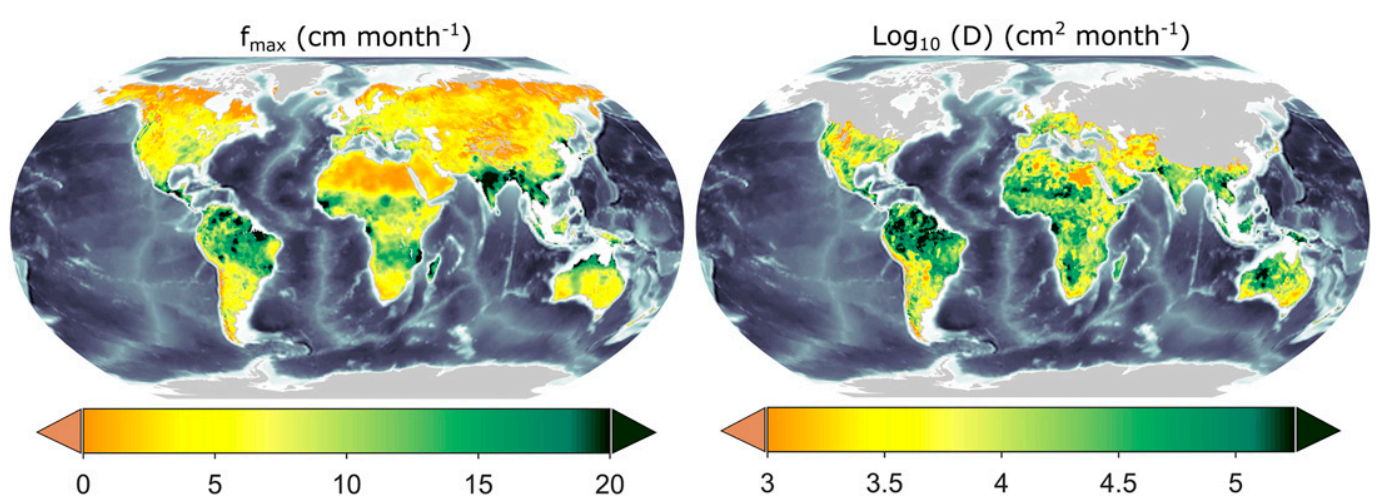

FIG. 1. Global distribution of the (left) maximum net water flux $f_{\max }$ used in Eq. (6) and (right) the soil water diffusivity parameter $D$ resulting from Eq. (6).

To that end, assuming that the year-to-year variability of runoff is small, we filled the missing runoff data with a 4-yr mean (e.g., $R$ in January 2015 was approximated as the mean of $R$ in Januaries 2011, 2012, 2013, 2014). The obtained SMAP-based $D$ map (not shown for brevity) is similar to the map depicted in Fig. 1b, with a global relative mean absolute deviation of less than $3.85 \%$ in log-space. This consistency indicates applicability of the proposed model across different satellite SM products with minimal calibration requirements. Note that the same SMOS-based $D$ map (Fig. 1b) is used for all following results.

Figure 2 depicts the global estimates of $\mathrm{NWF}_{\mathrm{SMOS}}$ (new approach), $\mathrm{NWF}_{\mathrm{RES}}$, and GRACE $d S / d t$, for January and July 2014. There is generally a good agreement between the spatial patterns of these fluxes, indicating that the proposed physical model can parsimoniously retrieve global NWF solely from satellite near-surface soil moisture retrievals, despite the introduced simplifications. A noticeable mismatch between the proposed approach and the other two products is observed for a few regions near the equator, such as western Brazil and central Africa. These areas are covered with dense vegetation and are known for large vegetation opacity, which increases the uncertainty in microwave satellite SM retrievals (Vittucci et al. 2016). Unlike in the residual approach, the irrigation water is implicitly accounted for in the new NWF estimates due to its effect on SM. Therefore, the role of irrigated agriculture can be another source for the deviation between these two methods, for example, in the northern part of India, Spain, Portugal, and France, where $\mathrm{NWF}_{\text {SMOS }}$ is generally larger than $\mathrm{NWF}_{\mathrm{RES}}$.

As shown in Eq. (5), the modeled NWF at a given time $t^{\prime}$ depends on the SM history from $t=0$ to $t=t^{\prime}$. Hence, even a single missing monthly SM value in a pixel can render the NWF estimation infeasible. This explains the missing $\mathrm{NWF}_{\mathrm{SMOS}}$ values for high latitude areas, where
SM cannot be retrieved accurately when the soil is frozen. Accordingly, snow-covered surfaces will result in undefined values and will be automatically masked, which alleviates concerns about the inadequacy of the linearized Richards' equation for simulating snowpack dynamics and its contribution to NWF.

Figures $3 \mathrm{a}$ and $3 \mathrm{~b}$ show the coefficients of determination $\left(R^{2}\right)$ between SMOS and SMAP SM and their corresponding NWF time series. As expected, while high correlations between SM data exist for most pixels, low correlations still occur for areas with dense vegetation and high radio frequency interference, and deserts where the signal-to-noise ratio is low (Wigneron et al. 2017; Al-Yaari et al. 2017). For areas where the SMOS and SMAP SM retrievals are in good agreement, there are strong correlations between $\mathrm{NWF}_{\mathrm{SMOS}}$ and $\mathrm{NWF}_{\mathrm{SMAP}}$, both derived based on the same $D$ map (Fig. 1b).

As shown in Fig. 3c, correlations between the $\mathrm{NWF}_{\mathrm{SMOS}}$ and $\mathrm{NWF}_{\mathrm{RES}}$ time series are also strong for many regions, especially when high-quality SM data are available. For some extreme climates, the observed correlations are low, which is attributable to the uncertainty associated with the microwave SM retrievals as well as to the introduced simplifying modeling assumptions. The transpiration by deeply rooted plants or upward water flow from shallow water tables, which are expected to be significant in wet regions (e.g., Amazon basin), are not accounted for in Eq. (5). In addition, the soil hydraulic functions $D(\theta)$ and $K(\theta)$ may be highly nonlinear and nonisothermal water and vapor flow can be significant in dry regions (e.g., Sahara), both violating the model assumptions.

As expected, correlations between $\mathrm{NWF}_{\mathrm{SMOS}}$ and GRACE $d S / d t$ (Fig. 3d) are comparatively weaker. This is partly due to the mismatch in spatial resolutions and the fact that GRACE mass change data are affected by additional fluxes such as human water abstraction, lateral 

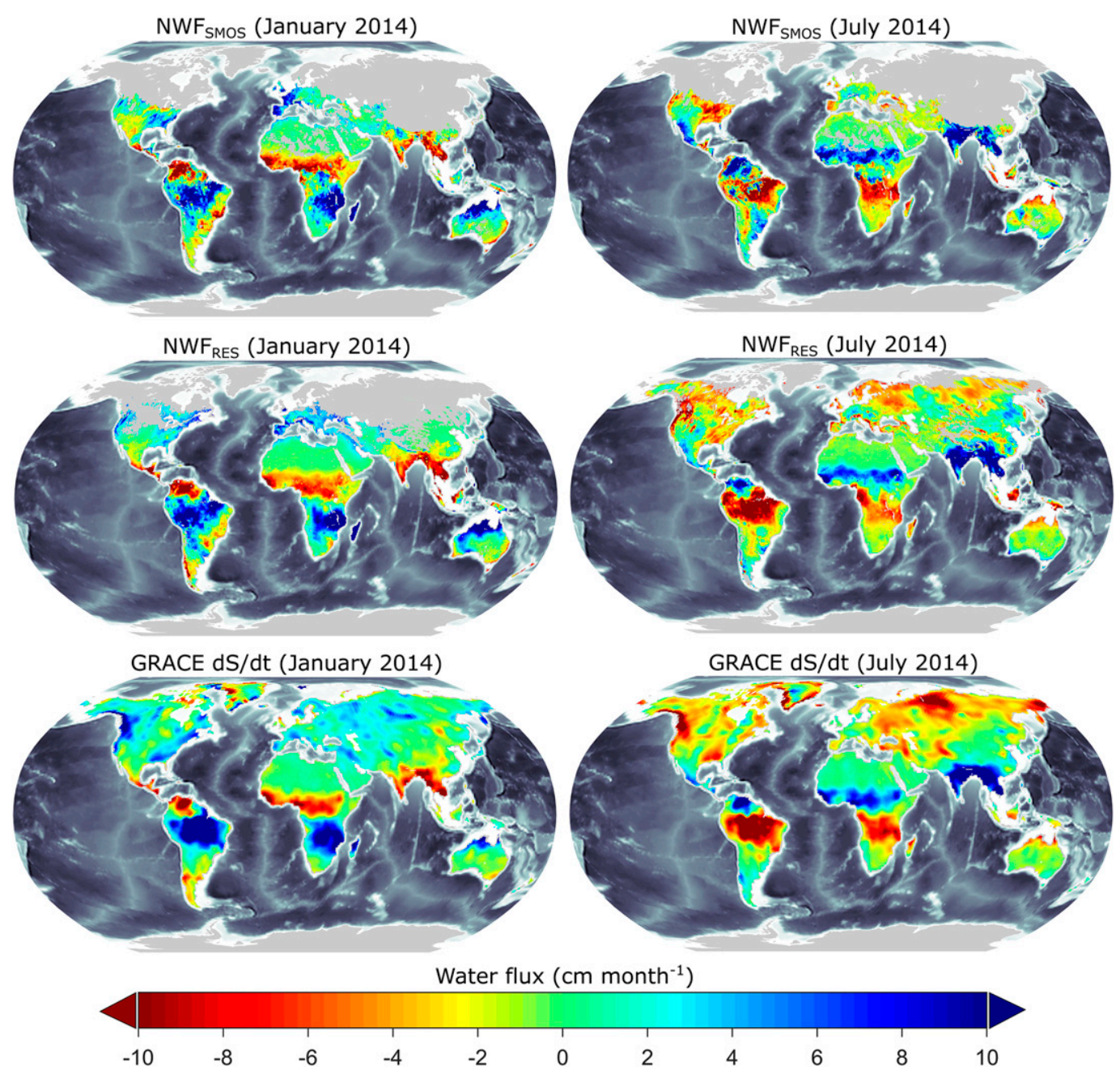

FIG. 2. Global distribution of (top) $\mathrm{NWF}_{\mathrm{SMOS}}$, (middle) $\mathrm{NWF}_{\mathrm{RES}}=P-\mathrm{ET}-R$, and (bottom) GRACE $d S / d t$ for (left) January and (right) July 2014. The masked pixels represent missing data from either the SM or ET products.

flow (e.g., coastal areas), and glacier melt (e.g., Chile, Argentina). The correlations are stronger, mostly in wetter regions, where a more pronounced covarying structure between NWF and $d S / d t$ is found due to a stronger seasonality.

The error statistics, including the bias and debiased root-mean-square deviation (RMSD) between $\mathrm{NWF}_{\mathrm{SMOS}}$ and $\mathrm{NWF}_{\mathrm{RES}}$ are mapped in Fig. 4. Although these error metrics show a similar range, the observed biases are much more important than the debiased RMSD values in the context of the water budget analysis. As shown later, a small bias in the NWF can lead to significant water mass closure error that accumulates with time. Hence, the observed biases in Fig. 4 are consequential in the context of water budget analysis, while they might be reasonable in terms of individual flux estimations (e.g., $P$ or ET). We discuss later whether the biases belong to $\mathrm{NWF}_{\mathrm{SMOS}}$ or $\mathrm{NWF}_{\mathrm{RES}}$.
Time series of spatially averaged SM values and estimated NWF values for six geographic regions (i.e., Asia, Australia, North Africa, South Africa, North America, and South America) are depicted in Fig. 5 with associated statistical metrics listed in Table 1 . While the SMAP SM retrievals are slightly higher than the SMOS retrievals, they are strongly correlated. Nevertheless, the modeled $\mathrm{NWF}_{\mathrm{SMOS}}$ and $\mathrm{NWF}_{\mathrm{SMAP}}$ values closely match for all investigated regions, indicating that the NWF model is not sensitive to potential SM biases. This is because the NWF depends on the SM deviation from the mean, that is, $\theta-\theta_{\infty}$ in Eq. (3), and not on the absolute SM value. It should be noted that the observed deviations at the onset of the $\mathrm{NWF}_{\mathrm{SMAP}}$ time series are due to the spin-up time ( $\sim 2$ months) of the NWF model to relax effects of the initial conditions, assumed as uniform SM profile in the derivation of Eq. (5). The good agreement between $\mathrm{NWF}_{\mathrm{SMO}}$ and $\mathrm{NWF}_{\mathrm{SMAP}}$, 
a) SMOS SM vS. SMAP SM

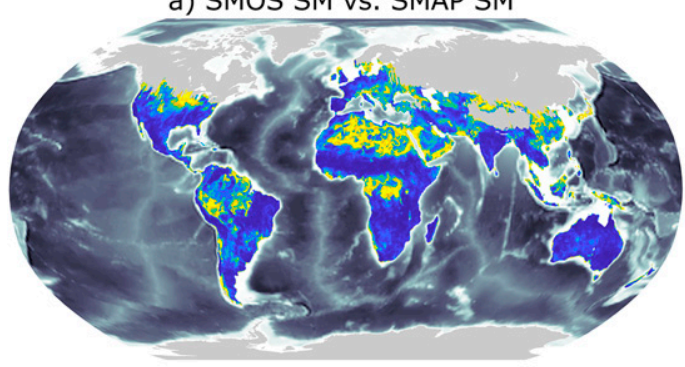

c) $N W F_{\text {SMOS }}$ VS. NWF

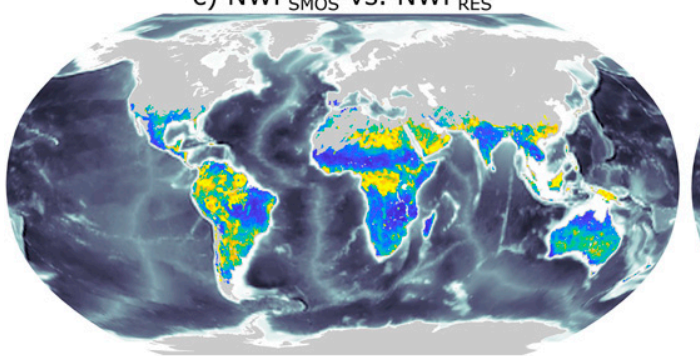

b) $N_{W} F_{S M O S}$ VS. NWF

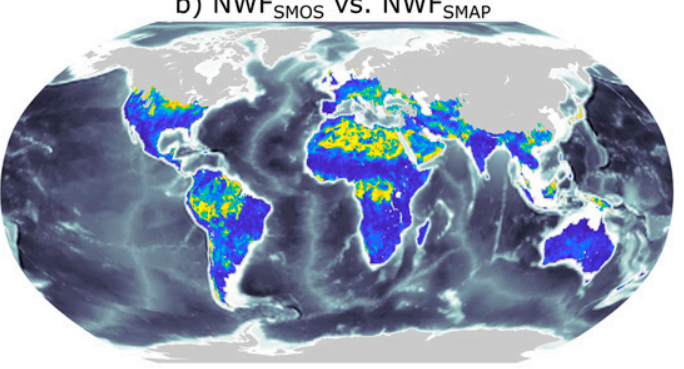

d) $\mathrm{NWF}_{\text {SMOS }}$ vs. GRACE dS/dt

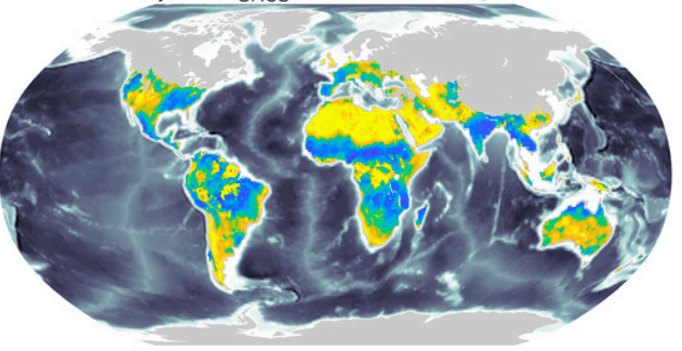

Coefficient of determination $\mathrm{R}^{2}$

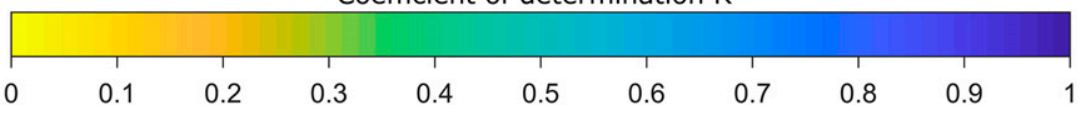

FIG. 3. Coefficient of determination $R^{2}$ for monthly (a) SMOS and SMAP soil moisture retrievals, (b) NWF SMOS and $\mathrm{NWF}_{\mathrm{SMAP}}$, (c) $\mathrm{NWF}_{\mathrm{SMOS}}$ and $\mathrm{NWF}_{\mathrm{RES}}=P-\mathrm{ET}-R$, and (d) $\mathrm{NWF}_{\mathrm{SMOS}}$ and GRACE $d S / d t$.

obtained with the same $D$ values (Fig. 1b), provides further evidence for the robustness of the presented calibration method. It also indicates that the derived diffusivity parameter (Fig. 1b) does not significantly vary over time and among various soil moisture products.

The $\mathrm{NWF}_{\mathrm{SMOS}}$ and $\mathrm{NWF}_{\mathrm{RES}}$ values are generally in close agreement in terms of seasonal and interannual variations. However, within the context of the analysis of the subsurface water balance, maintaining the mass balance is more important than capturing the temporal NWF dynamics. The original $\mathrm{NWF}_{\mathrm{RES}}$ time series can be calculated by adding the mean values (dashed straight lines) to the debiased $\mathrm{NWF}_{\mathrm{RES}}$ time series shown in Fig. 5. While the bias in most cases is significantly smaller than the amplitude of the seasonal NWF variations, when integrated over time, the small systematic biases can lead to significant water balance closure errors. This problem is illustrated in Fig. 6, where the cumulative $\mathrm{NWF}_{\mathrm{RES}}$ departs from the TWS anomaly observed by GRACE for most geographic regions, while the cumulative $\mathrm{NWF}_{\mathrm{SMOS}}$ is in reasonable agreement with the TWS anomaly. As discussed above, while the TWS anomaly is highly correlated with the cumulative NWF, they are not the same, as they are
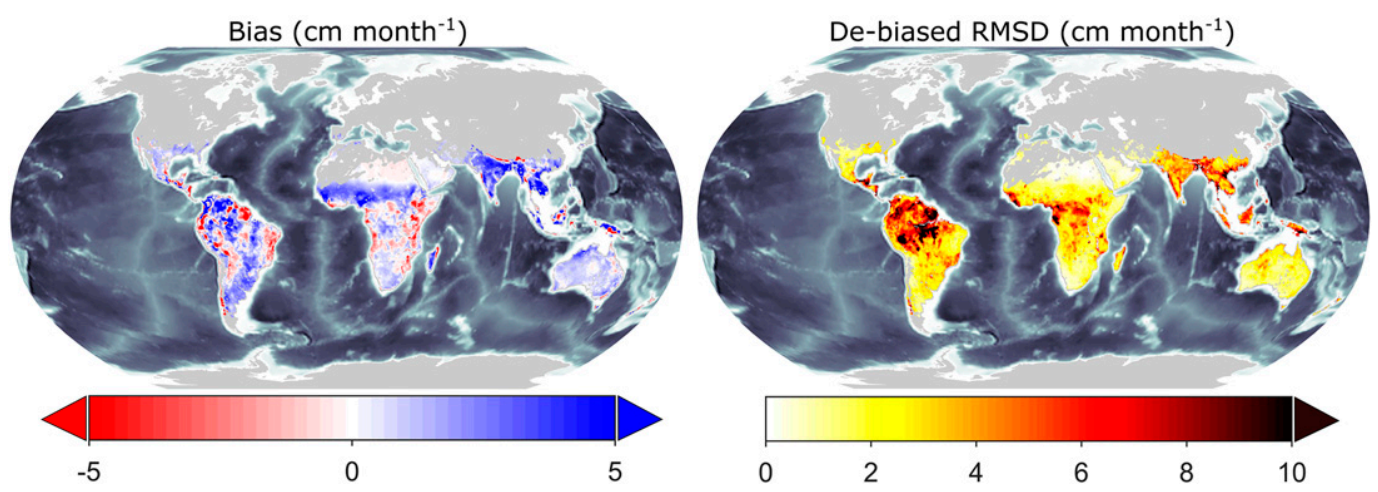

FIG. 4. (left) Bias defined as the temporal mean of $\mathrm{NWF}_{\mathrm{RES}}-\mathrm{NWF}_{\mathrm{SMOS}}$ and (right) debiased RMSD between

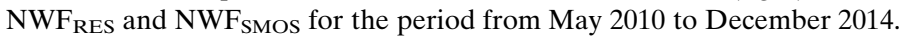




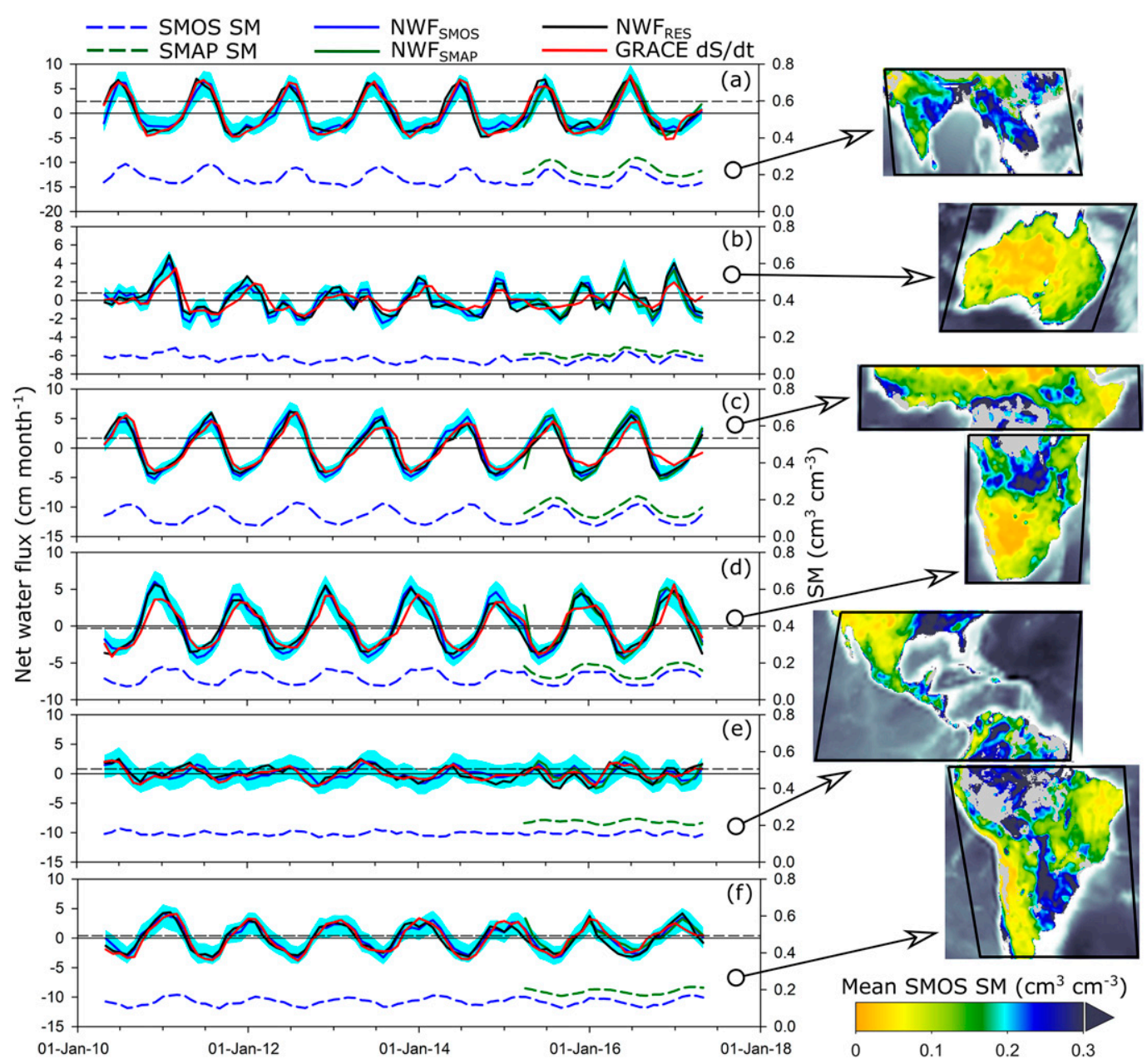

FIG. 5. Time series of studied soil moisture and water fluxes spatially averaged for (a) Asia, (b) Australia, (c) North Africa, (d) South Africa, (e) North America, and (f) South America. The dashed black straight lines represent the mean (bias) of the original $\mathrm{NWF}_{\mathrm{RES}}(P-\mathrm{ET}-R)$ values. The cyan shaded bands show the $\mathrm{NWF}_{\mathrm{SMO}}$ uncertainty bounds associated with the combined $\pm 10 \%$ uncertainty in monthly soil moisture and $\pm 20 \%$ uncertainty in $f_{\max }$ used in Eq. (6). The masked pixels are associated with uncertain SM data diagnosed from weak correlations $\left(R^{2}<0.5\right)$ between SMOS and SMAP retrievals.

composed of different flux components. This is why the deviation between $\mathrm{NWF}_{\mathrm{SMOS}}$ and the TWS anomaly in Fig. 6 should not be solely related to potential modeling or measurement errors. The deviations are within a few centimeters for most cases, which is consistent with the TWS trends reported in Rodell et al. (2018), who related the trends to climate variability (e.g., surface water changes) and/or anthropogenic activities (e.g., groundwater abstraction). In contrast, the differences between cumulative $\mathrm{NWF}_{\mathrm{RES}}$ and the TWS

TABLE 1. Statistical measures associated with the data shown in Fig. 5.

\begin{tabular}{|c|c|c|c|c|c|c|}
\hline \multirow[b]{2}{*}{ Region } & \multicolumn{3}{|c|}{$R^{2}$ for $\mathrm{NWF}_{\mathrm{SMOS}} \mathrm{vs}$} & \multicolumn{3}{|c|}{ RMSD (cm month ${ }^{-1}$ ) for $\mathrm{NWF}_{\mathrm{SMOS}} \mathrm{vs}$} \\
\hline & $\mathrm{NWF}_{\text {SMAP }}$ & $\mathrm{NWF}_{\text {RES }}$ & $d S / d t$ & $\mathrm{NWF}_{\text {SMAP }}$ & $\mathrm{NWF}_{\text {RES }}$ & $d S / d t$ \\
\hline Asia & 0.94 & 0.90 & 0.91 & 1.06 & 1.48 & 1.42 \\
\hline Australia & 0.97 & 0.87 & 0.56 & 0.31 & 0.61 & 1.12 \\
\hline North Africa & 0.97 & 0.96 & 0.89 & 0.82 & 0.82 & 1.35 \\
\hline South Africa & 0.96 & 0.95 & 0.86 & 0.80 & 0.79 & 1.36 \\
\hline North America & 0.96 & 0.45 & 0.59 & 0.68 & 1.22 & 0.98 \\
\hline South America & 0.91 & 0.91 & 0.89 & 0.82 & 0.81 & 1.01 \\
\hline
\end{tabular}




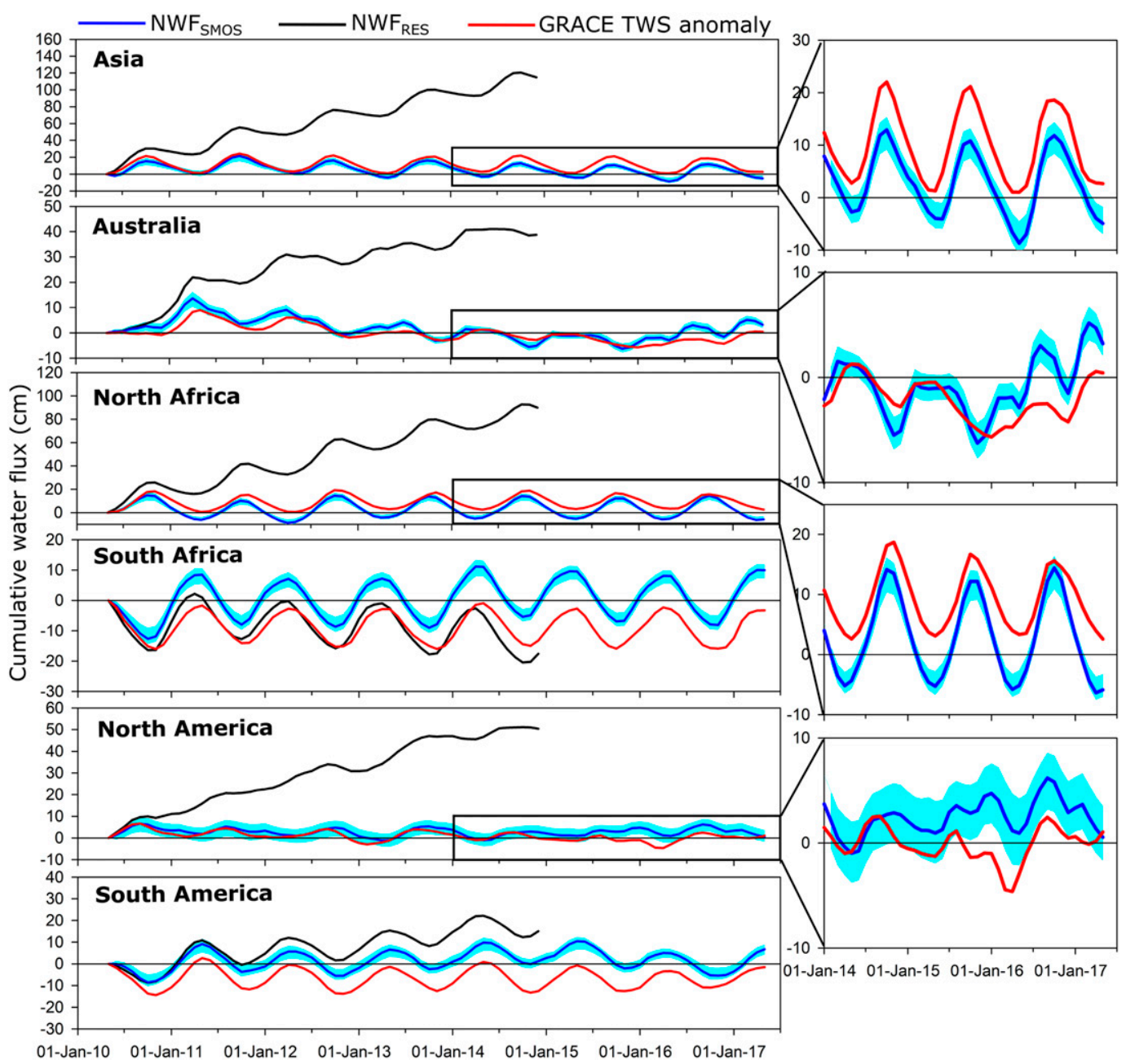

FIG. 6. Time series of cumulative water fluxes calculated from the flux rates shown in Fig. 5. The cyan shaded bands show the $\mathrm{NWF}_{\mathrm{SMOS}}$ uncertainty bounds associated with the combined $\pm 10 \%$ uncertainty in monthly soil moisture and $\pm 20 \%$ uncertainty in $f_{\max }$ used in Eq. (6).

anomaly are well beyond the reported TWS trends and most likely related to the mass balance errors because of unknown uncertainties and biases in $P, \mathrm{ET}$, and $R$ data.

From a physical point of view, conservation of mass is expected for the NWF model in Eq. (5), if there is no sink (i.e., plant uptake, human extraction) and lateral subsurface flow is negligible. This is inherent in Richards' equation, which is derived by combining the continuity principle (i.e., conservation of mass) and the Buckingham-Darcy law. Furthermore, the NWF is directly derived from a single data source, the nearsurface soil moisture. Similarly, a closure problem is not expected in the residual approach when applying reanalysis data (e.g., Rodell et al. 2004) or other datasets constrained to the continuity principle (Rodell et al. 2015; Pellet et al. 2019). However, the problem is unavoidable when independent satellite observations and ground-based $P, \mathrm{ET}$, and $R$ measurements are considered.

A sensitivity analysis, not shown here for brevity, indicates that the NWF computation error is proportional to the error of $f_{\max }$, since $f_{\max }$ acts like a scaling factor in the NWF model. For example, increasing $f_{\max }$ by $20 \%$ will lead to about $20 \%$ increase in the long-term NWF mean. Consequently, the subsurface water budget closure based on this approach is linearly sensitive to the model parameters and the model parameters only change the "magnitude" of the estimated long-term NWF mean, rather than its "sign" (i.e., whether water is gained or lost).

Noticeably, the ability to directly estimate NWF provides a new means to retrieve components of the surface water balance, such as infiltration and runoff, directly from satellite observations. As illustrated in 


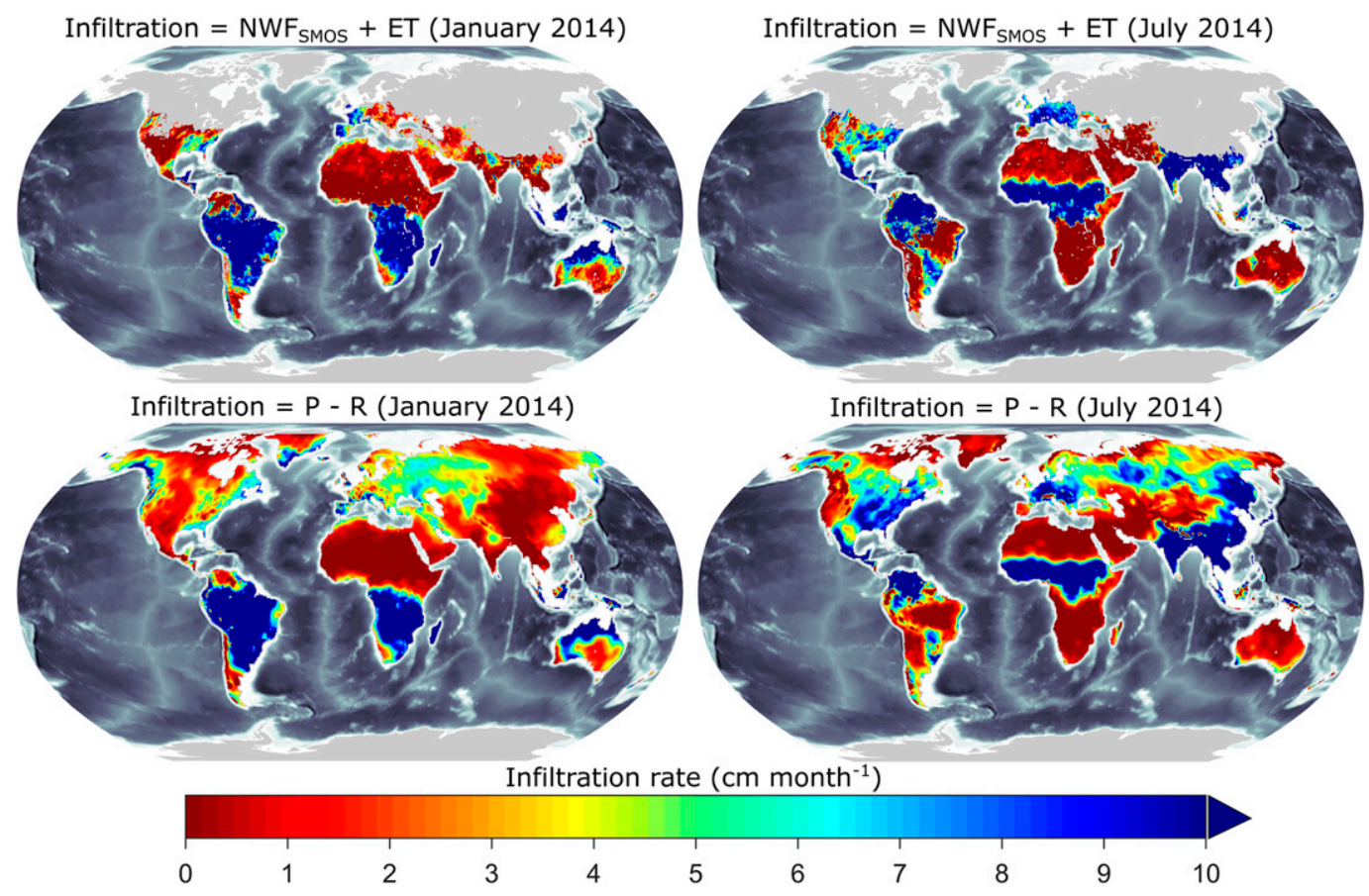

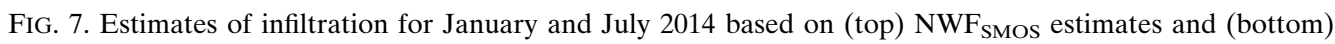
existing data products. The precipitation $P$ derives from the Global Precipitation Climatology Project (GPCP), evapotranspiration (ET) is from the Priestly-Taylor Jet Propulsion Laboratory (PTJPL), and the runoff $R$ is obtained from the Global Runoff Reconstruction (GRUN). The bias map shown in Fig. 4 quantifies the mean deviation between the two approaches $\left(P-\mathrm{ET}-R-\mathrm{NWF}_{\mathrm{SMOS}}\right)$.

Fig. 7, combining ET with NWF estimates enables calculation of infiltration $\left(I=\mathrm{NWF}_{\mathrm{SMOS}}+\mathrm{ET}\right)$, which currently is challenging to estimate because of the lack of real-time runoff data (Tourian et al. 2013; Lorenz et al. 2014; Ghiggi et al. 2019b). In addition, runoff can be estimated from the infiltration estimates and precipitation data $(R=P-I)$. As observed, the infiltration estimated with this approach (Fig. 7, top) is in reasonable agreement with GPCP and GRUN products (Fig. 7, bottom). However, it needs to be mentioned that the estimates are not free of uncertainty because they are based on uncertain ancillary data of ET as well as NWF data that are calibrated with the maximum $\mathrm{NWF}_{\text {RES }}$. The observed deviations in Fig. 7 are most likely due to such uncertainties and are equal to the biases $\left(\mathrm{NWF}_{\mathrm{RES}}-\mathrm{NWF}_{\mathrm{SMOS}}\right)$ shown in Fig. 4 . The results presented in Fig. 7 should be viewed as a proof of concept for the applicability of the NWF model for estimation of infiltration and runoff, and future work is essential for a thorough evaluation of these estimates.

\section{Conclusions}

We introduced a new parsimonious modeling paradigm that enables the inference of global land surface net water flux (NWF) from satellite soil moisture products. Direct estimates of NWF with this analytical approach show similar spatial patterns and temporal dynamics as the indirect estimates from the residual approach, $\mathrm{NWF}_{\mathrm{RES}}=P-\mathrm{ET}-R$. However, the presented model provides more robust estimates than the residual method in terms of mass conservation. Accordingly, the proposed model provides a new opportunity to estimate the long-term cumulative NWF for groundwater depletion/recharge assessment and to potentially reduce uncertainty in groundwater storage estimates. Results of this study demonstrate that satellite soil moisture retrievals, despite their shallow vertical support, contain sufficient information to reveal dynamics of the deeper subsurface water in response to the surface net water flux, which is consistent with the Koster et al. (2018) finding that "near-surface soil moisture retrievals contain, all by themselves, information that can be used to estimate large-scale water budgets."

The proposed approach is based on a simple homogenous bare soil model that does not explicitly account for transpiration by deeply rooted plants. Thus, the presented results over wet climate regimes with strong seasonal transpiration flux are expected to be highly uncertain. Future research is needed to advance this 
modeling paradigm to explicitly account for the root water uptake as well as to include more realistic soil water flow properties and processes such as (i) nonlinear soil hydraulic functions, (ii) soil layering, (iii) nonisothermal water and vapor flow, and (iv) upward flow from shallow water tables. Because an analytical solution to such complex processes is likely not feasible, incorporation of above properties and processes may be achieved with a new numerical model amenable to use near-surface soil moisture data (an internal condition) to simulate the surface water flux (a boundary condition).

The expected correlation between the cumulative NWF obtained with the proposed approach and the GRACE-observed TWS anomaly signify that the proposed model is capable of retrieving physically consistent NWF at a monthly time scale. Understanding and interpreting the differences between these two fluxes are expected to reveal important information about the contributions of natural and anthropogenic drivers to subsurface water storage changes, which is a subject of ongoing research.

Acknowledgments. MS, AE, and LG acknowledge support from the National Aeronautics and Space Administration (NASA) Terrestrial Hydrology Program (THP, 80NSSC18K152) through Dr. J. Entin and the New (Early Career) Investigator Program (NIP, 80NSSC18K0742) through Dr. A. Leidner and Dr. T. Lee. SBJ and MT acknowledge funding from National Science Foundation (NSF) Grants 1521469 and 1521164. MT and EB acknowledge support from the University of Arizona (UA) College of Agriculture and Life Sciences (CALS) Innovation Venture Investment Project (iVIP). JBF and AJP contributed to this work from the Jet Propulsion Laboratory, California Institute of Technology, under a contract with NASA and acknowledge support by the NASA SUSMAP program.

\section{APPENDIX}

\section{Steps for Calculating NWF from Satellite SM Retrievals}

1) Assume $z=2.5 \mathrm{~cm}, k=0.3 \mathrm{~cm} \mathrm{month}^{-1}$, and $D=$ $3000 \mathrm{~cm}^{2}$ month ${ }^{-1}$ for all pixels.

2) Calculate $\theta_{\infty}$ for each pixel as the temporal mean of SM for the entire study period (2010-17 in this study).

3) Compute the initial time series of NWF [i.e., variable $f$ in Eq. (3)] for each pixel using Eq. (5) based on SM data and the parameters from steps 1 and 2.

4) Obtain $f_{\max }^{\prime}$ for each pixel as the maximum of the initial NWF estimates obtained in step 3 during the calibration period (2010-14 in this study).
5) Set $f_{\max }$ at each pixel as the maximum of the debiased $\mathrm{NWF}_{\mathrm{RES}}$ during the calibration period (2010-14 in this study).

6) Determine $D$ for each pixel using Eq. (6) with $D^{\prime}=3000 \mathrm{~cm}^{2}$ month $^{-1}, f_{\max }^{\prime}$ from step 4 , and $f_{\max }$ from step 5 .

7) Recalculate NWF time series for each pixel using Eq. (5) based on SM data, $D$ from step 6 , and $z, k$, and $\theta_{\infty}$ from steps 1 and 2 .

\section{REFERENCES}

Adler, R. F., and Coauthors, 2003: The version-2 Global Precipitation Climatology Project (GPCP) monthly precipitation analysis (1979-present). J. Hydrometeor., 4, 1147-1167, https://doi.org/ 10.1175/1525-7541(2003)004<1147:TVGPCP $>2.0$. CO;2.

Akbar, R., D. Short Gianotti, K. A. McColl, E. Haghighi, G. D. Salvucci, and D. Entekhabi, 2018: Hydrological storage length scales represented by remote sensing estimates of soil moisture and precipitation. Water Resour. Res., 54, 1476-1492, https://doi.org/10.1002/2017WR021508.

_ D. J. Short Gianotti, G. D. Salvucci, and D. Entekhabi, 2019: Mapped hydroclimatology of evapotranspiration and drainage runoff using SMAP brightness temperature observations and precipitation information. Water Resour. Res., 55, 3391-3413, https://doi.org/10.1029/2018WR024459.

Al-Yaari, A., and Coauthors, 2017: Evaluating soil moisture retrievals from ESA's SMOS and NASA's SMAP brightness temperature datasets. Remote Sens. Environ., 193, 257-273, https://doi.org/10.1016/j.rse.2017.03.010.

Armanios, D. E., and J. B. Fisher, 2014: Measuring water availability with limited ground data: Assessing the feasibility of an entirely remote-sensing-based hydrologic budget of the Rufiji Basin, Tanzania, using TRMM, GRACE, MODIS, SRB, and AIRS. Hydrol. Processes, 28, 853-867, https://doi.org/10.1002/ hyp. 9611 .

Badgley, G., J. B. Fisher, C. Jiménez, K. P. Tu, and R. Vinukollu, 2015: On uncertainty in global terrestrial evapotranspiration estimates from choice of input forcing datasets. J. Hydrometeor., 16, 1449-1455, https://doi.org/10.1175/ JHM-D-14-0040.1.

Baldocchi, D., S. Ma, D. Szutu, and J. Verfaillie, 2016: AmeriFlux USTon Tonzi Ranch. AmeriFlux, University of California, accessed 28 January 2020, https://doi.org/10.17190/AMF/1245971.

Brocca, L., T. Moramarco, F. Melone, and W. Wagner, 2013: A new method for rainfall estimation through soil moisture observations. Geophys. Res. Lett., 40, 853-858, https://doi.org/ 10.1002/grl.50173.

_- and Coauthors, 2014: Soil as a natural rain gauge: Estimating global rainfall from satellite soil moisture data. J. Geophys. Res. Atmos., 119, 5128-5141, https://doi.org/ 10.1002/2014JD021489.

—, A. Tarpanelli, P. Filippucci, W. Dorigo, F. Zaussinger, A. Gruber, and D. Fernández-Prieto, 2018: How much water is used for irrigation? A new approach exploiting coarse resolution satellite soil moisture products. Int. J. Appl. Earth Obs. Geoinf., 73, 752-766, https://doi.org/10.1016/j.jag.2018.08.023.

Crow, W. T., E. Han, D. Ryu, C. R. Hain, and M. C. Anderson, 2017: Estimating annual water storage variations in mediumscale (2000-10000 $\mathrm{km}^{2}$ ) basins using microwave-based soil 
moisture retrievals. Hydrol. Earth Syst. Sci., 21, 1849-1862, https://doi.org/10.5194/hess-21-1849-2017.

Decker, M., and X. Zeng, 2009: Impact of modified Richards equation on global soil moisture simulation in the Community Land Model (CLM3. 5). J. Adv. Model. Earth Syst., 1 (3), https://doi.org/10.3894/JAMES.2009.1.5.

Demory, M. E., P. L. Vidale, M. J. Roberts, P. Berrisford, J. Strachan, R. Schiemann, and M. S. Mizielinski, 2014: The role of horizontal resolution in simulating drivers of the global hydrological cycle. Climate Dyn., 42, 2201-2225, https://doi.org/ 10.1007/s00382-013-1924-4.

Ebtehaj, A. M., and C. D. Kummerow, 2017: Microwave retrievals of terrestrial precipitation over snow-covered surfaces: A lesson from the GPM satellite. Geophys. Res. Lett., 44, 6154-6162, https://doi.org/10.1002/2017GL073451.

—_, R. L. Bras, and E. Foufoula-Georgiou, 2015: Shrunken locally linear embedding for passive microwave retrieval of precipitation. IEEE Trans. Geosci. Remote Sens., 53, 3720-3736, https://doi.org/10.1109/TGRS.2014.2382436.

Entekhabi, D., and Coauthors, 2010: The Soil Moisture Active Passive (SMAP) mission. Proc. IEEE, 98, 704-716, https:// doi.org/10.1109/JPROC.2010.2043918.

Famiglietti, J. S., and Coauthors, 2011: Satellites measure recent rates of groundwater depletion in California's Central Valley. Geophys. Res. Lett., 38, L03403, https://doi.org/ 10.1029/2010GL046442.

Fernandez-Moran, R., and Coauthors, 2017: SMOS-IC: An alternative SMOS soil moisture and vegetation optical depth product. Remote Sens., 9, 457, https://doi.org/10.3390/rs9050457.

Finch, J. W., 1998: Estimating direct groundwater recharge using a simple water balance model-sensitivity to land surface parameters. J. Hydrol., 211, 112-125, https://doi.org/10.1016/ S0022-1694(98)00225-X.

Fisher, J. B., K. P. Tu, and D. D. Baldocchi, 2008: Global estimates of the land-atmosphere water flux based on monthly AVHRR and ISLSCP-II data, validated at 16 FLUXNET sites. Remote Sens. Environ., 112, 901-919, https://doi.org/ 10.1016/j.rse.2007.06.025.

— Global requirements for ecosystem functioning, carbon and climate feedbacks, agricultural management, and water resources. Water Resour. Res., 53, 2618-2626, https://doi.org/ 10.1002/2016WR020175.

Getirana, A., S. Kumar, M. Girotto, and M. Rodell, 2017: Rivers and floodplains as key components of global terrestrial water storage variability. Geophys. Res. Lett., 44, 10359-10368, https://doi.org/10.1002/2017GL074684.

Ghiggi, G., S. I. Seneviratne, V. Humphrey, and L. Gudmundsson, 2019a: GRUN: Global Runoff Reconstruction (GRUN_v1). ETH Zurich, accessed 28 January 2020, https://doi.org/ 10.3929/ethz-b-000324386.

- V. Humphrey, S. I. Seneviratne, and L. Gudmundsson, 2019b: GRUN: An observations-based global gridded runoff dataset from 1902 to 2014. Earth Syst. Sci. Data, 11, 1655-1674, https://doi.org/10.5194/essd-11-1655-2019.

Gurdak, J. J., 2017: Climate-induced pumping. Nat. Geosci., 10, 71, https://doi.org/10.1038/ngeo2885.

Hengl, T., and Coauthors, 2014: SoilGrids1km-Global soil information based on automated mapping. PLOS ONE, 9, e105992, https://doi.org/10.1371/journal.pone.0105992.

Hou, A. Y., and Coauthors, 2014: The global precipitation measurement mission. Bull. Amer. Meteor. Soc., 95, 701-722, https:// doi.org/10.1175/BAMS-D-13-00164.1.
Jalilvand, E., M. Tajrishy, S. A. G. Z. Hashemi, and L. Brocca, 2019: Quantification of irrigation water using remote sensing of soil moisture in a semi-arid region. Remote Sens. Environ., 231, 111226, https://doi.org/10.1016/j.rse.2019.111226.

Kerr, Y. H., P. Waldteufel, J. P. Wigneron, J. A. M. J. Martinuzzi, J. Font, and M. Berger, 2001: Soil moisture retrieval from space: The Soil Moisture and Ocean Salinity (SMOS) mission. IEEE Trans. Geosci. Remote Sens., 39, 1729-1735, https:// doi.org/10.1109/36.942551.

Konikow, L. F., 2011: Contribution of global groundwater depletion since 1900 to sea-level rise. Geophys. Res. Lett., 38, L17401, https://doi.org/10.1029/2011GL048604.

Koster, R. D., L. Brocca, W. T. Crow, M. S. Burgin, and G. J. De Lannoy, 2016: Precipitation estimation using L-band and C-band soil moisture retrievals. Water Resour. Res., 52, 72137225, https://doi.org/10.1002/2016WR019024.

— W. T. Crow, R. H. Reichle, and S. P. Mahanama, 2018: Estimating basin-scale water budgets with SMAP soil moisture data. Water Resour. Res., 54, 4228-4244, https://doi.org/ 10.1029/2018WR022669.

Lawston, P. M., J. A. Santanello Jr., and S. V. Kumar, 2017: Irrigation signals detected from SMAP soil moisture retrievals. Geophys. Res. Lett., 44, 11860-11 867, https://doi.org/10.1002/ 2017GL075733.

Liu, Y., and H. V. Gupta, 2007: Uncertainty in hydrologic modeling: Toward an integrated data assimilation framework. Water Resour. Res., 43, W07401, https://doi.org/10.1029/ 2006WR005756.

Lorenz, C., H. Kunstmann, B. Devaraju, M. J. Tourian, N. Sneeuw, and J. Riegger, 2014: Large-scale runoff from landmasses: A global assessment of the closure of the hydrological and atmospheric water balances. J. Hydrometeor., 15, 2111-2139, https://doi.org/10.1175/JHM-D-13-0157.1.

McColl, K. A., and Coauthors, 2017: Global characterization of surface soil moisture drydowns. Geophys. Res. Lett., 44, 3682-3690, https://doi.org/10.1002/2017GL072819.

Montzka, C., M. Herbst, L. Weihermüller, A. Verhoef, and H. Vereecken, 2017: A global data set of soil hydraulic properties and sub-grid variability of soil water retention and hydraulic conductivity curves. Earth Syst. Sci. Data, 9, 529-543, https://doi.org/10.5194/essd-9-529-2017.

Moore, S., and J. B. Fisher, 2012: Challenges and opportunities in GRACE-based groundwater storage assessment and management: An example from Yemen. Water Resour. Manage., 26, 1425-1453, https://doi.org/10.1007/s11269-011-9966-z.

National Research Council, 2012: Challenges and Opportunities in the Hydrologic Sciences. National Academies Press, 200 pp.

Niu, G. Y., and Coauthors, 2011: The community Noah land surface model with multi-parameterization options (NoahMP): 1. Model description and evaluation with local-scale measurements. J. Geophys. Res., 116, D12109, https://doi.org/ 10.1029/2010JD015139.

Oleson, K. W., and Coauthors, 2008: Improvements to the Community Land Model and their impact on the hydrological cycle. J. Geophys. Res., 113, G01021, https://doi.org/10.1029/ 2007JG000563.

O'Neill, P. E., S. Chan, E. G. Njoku, T. Jackson, and R. Bindlish, 2018: SMAP enhanced L3 radiometer global daily $9 \mathrm{~km}$ EASE-grid soil moisture, version 2. NASA National Snow and Ice Data Center Distributed Active Archive Center, accessed 28 January 2020, https://doi.org/10.5067/RFKIZ5QY5ABN.

Padrón, R. S., L. Gudmundsson, and S. I. Seneviratne, 2019: Observational constraints reduce likelihood of extreme 
changes in multidecadal land water availability. Geophys. Res. Lett., 46, 736-744, https://doi.org/10.1029/2018GL080521.

Pellet, V., F. Aires, A. Mariotti, and D. Fernández-Prieto, 2018: Analyzing the Mediterranean water cycle via satellite data integration. Pure Appl. Geophys., 175, 3909-3937, https:// doi.org/10.1007/s00024-018-1912-z.

— , and Coauthors, 2019: Integrating multiple satellite observations into a coherent dataset to monitor the full water cycleApplication to the Mediterranean region. Hydrol. Earth Syst. Sci., 23, 465-491, https://doi.org/10.5194/hess-23-465-2019.

Polhamus, A., J. B. Fisher, and K. P. Tu, 2013: What controls the error structure in evapotranspiration models? Agric. For. Meteor., 169, 12-24, https://doi.org/10.1016/j.agrformet.2012.10.002.

Purdy, A. J., J. B. Fisher, M. L. Goulden, and J. S. Famiglietti, 2016: Ground heat flux: An analytical review of 6 models evaluated at 88 sites and globally. J. Geophys. Res. Biogeosci., 121,30453059, https://doi.org/10.1002/2016JG003591.

,,--- A. Colliander, G. Halverson, K. Tu, and J. S. Famiglietti, 2018: SMAP soil moisture improves global evapotranspiration. Remote Sens. Environ., 219, 1-14, https://doi.org/ 10.1016/j.rse.2018.09.023.

Richards, L. A., 1931: Capillary conduction of liquids through porous mediums. Physics, 1, 318-333, https://doi.org/10.1063/ 1.1745010 .

Richey, A. S., and Coauthors, 2015: Quantifying renewable groundwater stress with GRACE. Water Resour. Res., 51, 5217-5238, https://doi.org/10.1002/2015WR017349.

Rodell, M., and Coauthors, 2004: The Global Land Data Assimilation System. Bull. Amer. Meteor. Soc., 85, 381-394, https://doi.org/ 10.1175/BAMS-85-3-381.

__ I. Velicogna, and J. S. Famiglietti, 2009: Satellite-based estimates of groundwater depletion in India. Nature, 460, 999-1002, https://doi.org/10.1038/nature08238.

- and Coauthors, 2015: The observed state of the water cycle in the early twenty-first century. J. Climate, 28, 8289-8318, https://doi.org/10.1175/JCLI-D-14-00555.1.

— J. S. Famiglietti, D. N. Wiese, J. T. Reager, H. K. Beaudoing, F. W. Landerer, and M. H. Lo, 2018: Emerging trends in global freshwater availability. Nature, 565, 651-659, https://doi.org/ 10.1038/s41586-018-0831-6.

Sadeghi, M., M. Tuller, A. W. Warrick, E. Babaeian, K. Parajuli, M. R. Gohardoust, and S. B. Jones, 2019: An analytical model for estimation of land surface net water flux from near-surface soil moisture observations. J. Hydrol., 570, 26-37, https:// doi.org/10.1016/j.jhydrol.2018.12.038.

Save, H., S. Bettadpur, and B. D. Tapley, 2016: High-resolution CSR GRACE RL05 mascons. J. Geophys. Res. Solid Earth, 121, 7547-7569, https://doi.org/10.1002/2016JB013007.
Šimůnek, J., M. T. Van Genuchten, and M. Šejna, 2016: Recent developments and applications of the HYDRUS computer software packages. Vadose Zone J., 15, 1-25, https://doi.org/ 10.2136/vzj2016.04.0033.

Stephens, G. L., and C. D. Kummerow, 2007: The remote sensing of clouds and precipitation from space: A review. J. Atmos. Sci., 64, 3742-3765, https://doi.org/10.1175/2006JAS2375.1.

Tourian, M. J., N. Sneeuw, and A. Bárdossy, 2013: A quantile function approach to discharge estimation from satellite altimetry (ENVISAT). Water Resour. Res., 49, 4174-4186, https://doi.org/10.1002/wrcr.20348.

Vinukollu, R. K., E. F. Wood, C. R. Ferguson, and J. B. Fisher, 2011: Global estimates of evapotranspiration for climate studies using multi-sensor remote sensing data: Evaluation of three process-based approaches. Remote Sens. Environ., 115, 801-823, https://doi.org/10.1016/ j.rse.2010.11.006.

Vittucci, C., P. Ferrazzoli, Y. Kerr, P. Richaume, L. Guerriero, R. Rahmoune, and G. V. Laurin, 2016: SMOS retrieval over forests: Exploitation of optical depth and tests of soil moisture estimates. Remote Sens. Environ., 180, 115-127, https://doi.org/ 10.1016/j.rse.2016.03.004.

Wada, Y., L. P. H. Van Beek, and M. F. Bierkens, 2012: Nonsustainable groundwater sustaining irrigation: A global assessment. Water Resour. Res., 48, W00L06, https://doi.org/ 10.1029/2011WR010562.

Warrick, A. W., 1975: Analytical solutions to the one-dimensional linearized moisture flow equation for arbitrary input. Soil Sci., 120, 79-84, https://doi.org/10.1097/00010694-19750800000001.

Wigneron, J.-P., and Coauthors, 2017: Modelling the passive microwave signature from land surfaces: A review of recent results and application to the L-band SMOS \& SMAP soil moisture retrieval algorithms. Remote Sens. Environ., 192, 238-262, https://doi.org/10.1016/j.rse.2017.01.024.

Yeh, H. F., C. H. Lee, J. F. Chen, and W. P. Chen, 2007: Estimation of groundwater recharge using water balance model. Water Resour., 34, 153-162, https://doi.org/10.1134/ S0097807807020054.

Zaussinger, F., W. Dorigo, A. Gruber, A. Tarpanelli, P. Filippucci, and L. Brocca, 2019: Estimating irrigation water use over the contiguous United States by combining satellite and reanalysis soil moisture data. Hydrol. Earth Syst. Sci., 23, 897-923, https://doi.org/10.5194/hess-23-897-2019.

Zeng, X., and M. Decker, 2009: Improving the numerical solution of soil moisture-based Richards equation for land models with a deep or shallow water table. J. Hydrometeor., 10, 308-319, https://doi.org/10.1175/2008JHM1011.1. 